\title{
Tasas de nacimiento acumulativas con técnicas de reproducción asistida
}

\author{
Cumulative birth rates with assisted reproductive technologies
}

Luke, B. N Engl J Med 2012;366:2483-91.

\section{Objetivo}

Determinar las tasas acumulativas de recién nacidos vivos (RNV) en función de distintos métodos de reproducción asistida.

\section{Diseño}

Cohorte retrospectiva.

\section{Lugar}

Estados Unidos de Norteamérica.

\section{Pacientes}

Se utilizó el Sistema de Reporte de Resultados Clínicos (CORS) de la Sociedad de Tecnología de Reproducción Asistida (SART) que cubre el $90 \%$ de las clínicas de reproducción asistida.

Se incluyeron mujeres cuyo primer ciclo de tratamiento fue reportado entre el 01/01/2004 y el 31/12/2008. El seguimiento se hizo hasta diciembre de 2009. Se excluyeron pacientes que: iniciaran tratamiento en 2009 , que hubieren recibido un ciclo de tratamiento previo al periodo de inclusión, que estuvieran en un protocolo de investigación, que utilizaron embriones de banco, o un útero subrogado.

\section{Evaluación de factores pronósticos}

Se analizó la tasa de RNV con respecto a la edad de la paciente, la causa de infertilidad, si los ovocitos eran autólogos (propios) o donados, si los embriones eran frescos o descongelados, y el día en que se efectuó la embriotransferencia (día $2^{\circ}$ a $3^{\circ}$ ó $5^{\circ}$ a $6^{\circ}$ ).

Los datos fueron procesados en forma centralizada por investigadores ciegos a datos de las pacientes, aunque asociando los ciclos de reproducción con cada mujer.

\section{Medición de Resultados Principales}

Se consideró RNV a los nacimientos a partir de la semana 22 de gestación y que tuviesen 300 gramos o más de peso al nacer. Se realizaron dos tipos de estimaciones: la "conservadora", considerando aquellas pacientes que no regresaron a consultas posteriores como si no hubiesen tenido un resultado positivo; y una "óptima", que asumía que estas pacientes tuvieron una tasa similar a la de las pacientes seguidas efectivamente.

\section{Resultados Principales}

Se analizaron 471.208 ciclos en 246.740 pacientes, registrándose 140.859 partos. Aproximadamente $25 \%$ de las mujeres sin un nacido vivo en el primer ciclo no regresó para un segundo ciclo; y en ciclos posteriores, alrededor del 33\% tampoco regresó.

Las tasas de RNV se redujeron con la edad materna cuando se utilizaron ovocitos autólogos, pero no cuando se utilizaron donados.

Tabla 1. Tasas acumuladas de RNV en el tercer ciclo, utilizando ovocitos autólogos, según edad de las mujeres.

\begin{tabular}{c|c|c}
\multirow{2}{*}{$\begin{array}{c}\text { Edad de las } \\
\text { mujeres }\end{array}$} & \multicolumn{2}{|c}{ Tasas de RNV acumuladas } \\
\cline { 2 - 3 } & $\begin{array}{c}\text { Estimación } \\
\text { conservadora }\end{array}$ & $\begin{array}{c}\text { Estimación } \\
\text { optima }\end{array}$ \\
\hline Menores de 31 años & $63,30 \%$ & $74,60 \%$ \\
\hline 41 a 42 años & $18,60 \%$ & $27,80 \%$ \\
\hline Mayores de 42 años & $6,60 \%$ & $11,30 \%$ \\
\hline
\end{tabular}

Cuando se utilizaron ovocitos donados, las tasas fueron superiores al $60 \%$ y $80 \%$, respectivamente, para todas las edades. Las tasas fueron mayores con transferencias de embriones en estadio de blastocisto (día de transferencia $5^{\circ} \circ 6^{\circ}$ ) que con embriones tempranos (embriones de día $2^{\circ} \circ 3^{\circ}$ ).

En el tercer ciclo, las estimaciones conservadoras y óptimas fueron, respectivamente, $42,7 \%$ y $65,3 \%$ para la transferencia de embriones tempranos (días $2^{\circ}-3^{\circ}$ ) y $52,4 \%$ y $80,7 \%$ para blastocistos cuando se utilizaron ovocitos frescos autólogos.

\section{Conclusiones}

Las tasas de RNV se aproximan a la fecundidad natural si existen condiciones favorables de la paciente y embrión. Las tasas entre las mujeres mayores son más bajas cuando se utilizan ovocitos autólogos, pero son similares a las de mujeres jóvenes cuando se emplean ovocitos donados.

Fuente de financiamiento: National Institutes of Health, y SART.

\section{Comentario}

Este estudio nos brinda la posibilidad de conocer la probabilidad de éxito acumulada de las técnicas de reproducción asistida de alta complejidad, y no sólo la efectividad promedio por ciclo como habitualmente se reporta ${ }^{1,2}$. Esto resulta muy relevante para brindar consejo y asesoramiento más realista a las pacientes pensando en su futuro reproductivo, y no en el corto plazo de un estímulo único.

Técnicamente, el trabajo es muy prolijo, por lo que no amerita mayores comentarios. Lo más destacable de sus resultados es cómo influye negativamente la edad de las pacientes en la tasa de nacidos vivos cuando se utilizan ovocitos propios, siendo dramática la caída en mayores de 40 años. Es por esto que debemos evaluar el deseo o planes de embarazo de las pacientes antes de llegar a estas edades, a los fines de que ellas puedan tomar decisiones informadas y oportunas.

Por último, este estudio también nos muestra que aún en aquellas pacientes con edades avanzadas la tasa de nacidos vivos podría equipararse al de las mujeres jóvenes si se utilizan ovocitos donados (que provienen de pacientes jóvenes y fértiles). Por ello, es importante que podamos ofrecer esta alternativa a este grupo de pacientes cuando hayan fracasado luego de varios intentos (tres) con ovocitos propios. De esta forma podríamos evitarles mayores sufrimientos asociados con una alternativa que tenga muy pocas chances de ser efectiva en su caso particular, cambiándola por otra con perspectivas similares al de una mujer fértil ${ }^{3}$.

Romina Pesce [ Sección Medicina Reproductiva, Servicio de Ginecología del Hospital Italiano de Buenos Aires. romina.pesce@ hospitalitaliano.org.ar]

Pesce R. Tasas de nacimiento acumulativas con técnicas de reproducción asistida. Evid Act Prac Ambul. Jul-Set 2013;16(3):89. Comentado de: Luke B, Brown MB, Wantman E, et al. Cumulative Birth Rates with Linked Assisted Reproductive Technology Cycles. N Engl J Med 2012;366:248391. PMID: 22738098.

\section{Referencias}

1.Malizia BA, Hacker MR, Penizias A. Cumulative live birth rates after in vitro fertilization, New England Journal Med 2009; 360:236-43.

2. The Practice Comitee of the American Society for Reproductive Medicine. Aging and Infertility in women. Fertility And Sterility 2006;86(Suppl 4):48-52. 3.Steiner A, Paulson R. Oocyte Donation. Clinical Obstetrics and Gynecology 2006;49(1):44-54. 